\title{
Article \\ Strong Antimicrobial Effects of Xanthohumol and Beta-Acids from Hops against Clostridioides difficile Infection In Vivo
}

\author{
Radek Sleha $\left.{ }^{1}{ }^{(}\right)$, Vera Radochova $^{1}$, Alexander Mikyska ${ }^{2}{ }^{\circledR}$, Milan Houska $^{3}$, Radka Bolehovska ${ }^{4}$, \\ Sylva Janovska ${ }^{1}{ }^{(0)}$, Jaroslav Pejchal ${ }^{5}{ }^{(\mathbb{D}}$, Lubica Muckova ${ }^{5}{ }^{(0)}$, Pavel Cermak ${ }^{6}$ and Pavel Bostik ${ }^{1,4,7, *(\mathbb{D})}$ \\ 1 Department of Epidemiology, Faculty of Military Health Sciences, University of Defence, \\ 50003 Hradec Kralove, Czech Republic; radek.sleha@unob.cz (R.S.); vera.radochova@unob.cz (V.R.); \\ sylva.janovska@unob.cz (S.J.) \\ 2 Research Institute of Brewing and Malting, 11000 Prague, Czech Republic; mikyska@beerresearch.cz \\ 3 Food Research Institute, 11000 Prague, Czech Republic; milan.houska@vupp.cz \\ 4 Institute of Clinical Microbiology, University Hospital, 50003 Hradec Kralove, Czech Republic; \\ radka.bolehovska@fnhk.cz \\ 5 Department of Toxicology and Military Pharmacy, Faculty of Military Health Sciences, University of Defence, \\ 50003 Hradec Kralove, Czech Republic; jaroslav.pejchal@unob.cz (J.P.); Lubica.Muckova@unob.cz (L.M.) \\ 6 Thomayer Hospital, 11000 Prague, Czech Republic; pavel.cermak@ftn.cz \\ 7 Department of Clinical Microbiology, Faculty of Medicine in Hradec Kralove, Charles University, \\ 50003 Hradec Kralove, Czech Republic \\ * Correspondence: pavel.bostik@unob.cz
}

check for

updates

Citation: Sleha, R.; Radochova, V.; Mikyska, A.; Houska, M.; Bolehovska, R.; Janovska, S.; Pejchal, J.; Muckova,

L.; Cermak, P.; Bostik, P. Strong

Antimicrobial Effects of Xanthohumol and Beta-Acids from Hops against Clostridioides difficile Infection In Vivo. Antibiotics 2021, 10, 392. https:// doi.org/10.3390/antibiotics10040392

Academic Editor: Ashish Pathak

Received: 25 February 2021

Accepted: 3 April 2021

Published: 6 April 2021

Publisher's Note: MDPI stays neutral with regard to jurisdictional claims in published maps and institutional affiliations.

Copyright: (C) 2021 by the authors. Licensee MDPI, Basel, Switzerland. This article is an open access article distributed under the terms and conditions of the Creative Commons Attribution (CC BY) license (https:/ / creativecommons.org/licenses/by/ $4.0 /)$.

\begin{abstract}
Clostridioides (C.) difficile is an important causative pathogen of nosocomial gastrointestinal infections in humans with an increasing incidence, morbidity, and mortality. The available treatment options against this pathogen are limited. The standard antibiotics are expensive, can promote emerging resistance, and the recurrence rate of the infection is high. Therefore, there is an urgent need for new approaches to meet these challenges. One of the possible treatment alternatives is to use compounds available in commonly used plants. In this study, purified extracts isolated from hops - alpha and beta acids and xanthohumol—were tested in vivo for their inhibitory effect against C. difficile. A rat model of the peroral intestinal infection by $C$. difficile has been developed. The results show that both xanthohumol and beta acids from hops exert a notable antimicrobial effect in the C. difficile infection. The xanthohumol application showed the most pronounced antimicrobial effect together with an improvement of local inflammatory signs in the large intestine. Thus, the hops compounds represent promising antimicrobial agents for the treatment of intestinal infections caused by C. difficile.
\end{abstract}

Keywords: hops; C. difficile; infection; rat model

\section{Introduction}

C. difficile (formerly Clostridium difficile) is an anaerobic, spore-forming Gram-positive bacterium, which is widely found in the mammalian gastrointestinal tract (GIT), including in humans. Its growth is under physiological circumstances suppressed by the intestinal microbiome. One of the main virulence factors of $C$. difficile is the ability to form aerotolerant spores allowing bacteria to persist within the host and to disseminate by patient-to-patient contact or environmental contamination. Clostridial toxins A and B represent other important pathogenetic factors. These exotoxins have enterotoxic and cytotoxic activity that cause primary symptoms of the disease [1-3].

C. difficile is opportunistic bacteria, a pathological role which usually manifests in hospital settings in patients with antibiotic treatment that alter the colonic microbiome. The extensive antibiotic resistance of $C$. difficile leads to its proliferation in the colon and toxin production. The other patient-related risk factors affecting this process are advanced age, increased severity of underlying illness, prior hospitalization, use of feeding tubes, 
gastrointestinal surgery, and therapy using proton-pump inhibitors. Clinical symptoms of C. difficile infection manifest by signs ranging from mild diarrhea to pseudomembranous colitis, toxic megacolon, bowel perforation, and sepsis $[4,5]$.

The treatment strategy of the $C$. difficile-induced infection depends on the health status of the patient and comorbidities. The first step in treating $C$. difficile is to discontinue the antibiotic therapy that triggered the $C$. difficile overgrowth leading to symptoms or, if necessary, to replace the antibiotic with another one. In intermediate and severe cases, antibiotics remain the recommended treatment. Vancomycin and metronidazole are the antibiotics of choice. They are the most efficient ones in clinical practice. The other drugs utilized in such cases include fidaxomicin, tigecycline, or teicoplanin. Recurrent $C$. difficile infections occur in up to $35 \%$ of cases due to the relapse of infection or reinfection with another strain [6-9]. Preserving physiological microbiome and microbial diversity in the gastrointestinal tract may prevent or even treat the disease. Other potential therapeutical modalities represent non-antibiotic therapies, such as the application of probiotics, intravenous immunoglobulins, and fecal transplants $[2,5,10]$.

However, the commonly used antibiotic therapy could induce bacterial resistance and create a burden for the patient. Therefore, effective non-antibiotic alternatives are urgently needed and have been a focus of research for several years, including plant derivatives. Among those, various hops extracts and individual hops compounds have been known for some time for their antimicrobial activity. Strong antimicrobial activity of hops compounds (isolated from Humulus lupulus L.), including xanthohumol or alfa- and beta-bitter acids, has been reported against $C$. difficile in vitro. With minimal inhibitory concentrations being close to commonly used antibiotics, these compounds may represent a potential alternative for treating C. difficile infections [11-16].

Various animals pretreated with antibiotic regimens followed by oral challenge with C. difficile have been used as suitable models for $C$. difficile-induced disease $[1,5,17-20]$.

The aim of this study was to determine the antibacterial properties of pure hops extracts of alpha- and beta-bitter acids and xanthohumol in C. difficile infection in vivo. For this purpose, a rat model of infection was developed.

\section{Results}

To evaluate the in vivo antibacterial effect of purified hops compounds, the experimental animals were first conditioned using an antibiotic regimen to clear their intestines from microflora and the endogenous $C$. difficile infection. The animals were then experimentally infected with a quantified dose of ribotyped hypervirulent $C$. difficile strain. Several different bacterial isolates were first tested for their pathogenicity in rats leading to the selection of the most pathogenic one (data not shown). A total of 35 animals divided into five experimental groups were then monitored for both the general signs of $C$. difficile-induced disease and for the presence of the bacteria in feces. Prior to the infection of animals with the experimental strain, only two animals tested positive for the endogenous colonization with $C$. difficile. Both of them belonged to the group subsequently treated with beta-bitter acids. One of these rats died during the experiment. Within three days post-infection, all animals were culture positive for the presence of vegetative form or spores of $C$. difficile. The general clinical symptoms of $C$. difficile infection were also observed in all animals (apathy, bristle coat). At this time point, the administration of antibacterial substances started (xanthohumol, beta-acids, xanthohumol + beta-acids, or vancomycin), except for the control group which received no treatment. Alpha bitter acids were not included in this study as they showed only a limited effectivity in vitro [13] and no effect in a preliminary experiment in vivo (data not shown).

The body weight of each animal was monitored during the entire experiment. Until day 3 post-infection, all infected animals suffered weight loss, and several rats also exhibited symptoms of diarrhea. After the onset of antimicrobial treatment, the body weight of each treated animal started to improve rapidly. As illustrated in Figure 1, all tested hops compounds and vancomycin effectively stopped further weight loss of animals and led 
to the normalization of their body weight compared to the untreated control group. All treated groups showed significant differences in body weight on days 7,8 , and $9(p<0.05)$ compared to the untreated control. The most profound and rapid positive effect of the hops compound was observed especially in the beta-bitter acid group. This was despite the fact that the animals in all three hops compound-treated groups exhibited the most pronounced weight loss after the infection but before the treatment. The other clinical symptoms in animals in the treated groups improved as well.

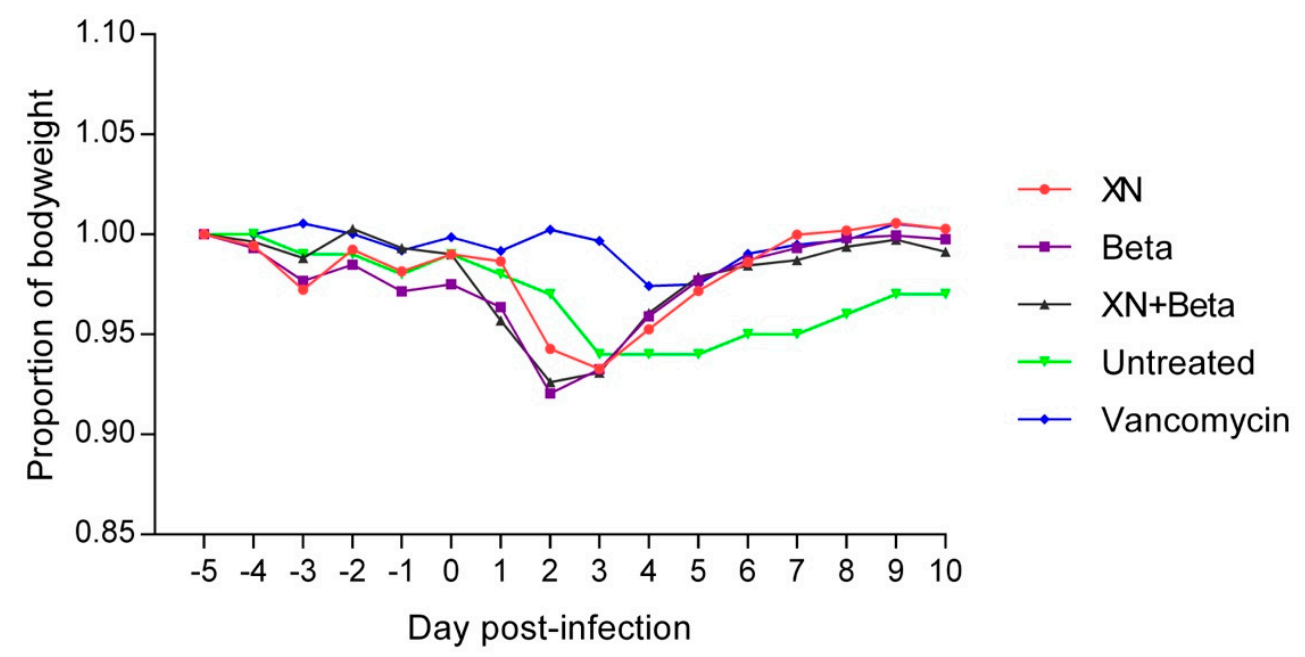

Figure 1. The proportion of body weight of infected rats during the C. difficile infection. Data are presented as means of the animal body weights at the individual time points relative to their body weight at the onset of the experiment (day-5). The animals were infected on day 0 , and treatments started on day 3. XN-xanthohumol, Beta-beta-acids.

The quantitative determination of $C$. difficile in fecal samples showed the ability of tested compounds to reduce the bacterial load (Figure 2). During the treatment period (samples collected on days 3, 5, 7, and 9 post-infection), all three hops-compound treatment modalities showed similar inhibitory effects when compared to the untreated control. The reduction of the bacterial load was observed from day 3 post-infection. In all three treatment groups the differences in bacterial load of $C$. difficile were significant $(p<0.05)$ when compared to the untreated controls. Treatment by vancomycin in the positive control group showed a rapid decline of the bacterial load from day 5 (Figure 2).

We further evaluated the effect of treatments on the infection in intestines in experimental animals both at the macroscopical and microscopical levels after the termination of the experiment. The macroscopical evaluation showed marked hyperemia and swelling of the bowel in the animals from the untreated group. All the administered treatments led to a physiological bowel appearance after the termination of the experiment. Representative examples are shown in Figure 3. 


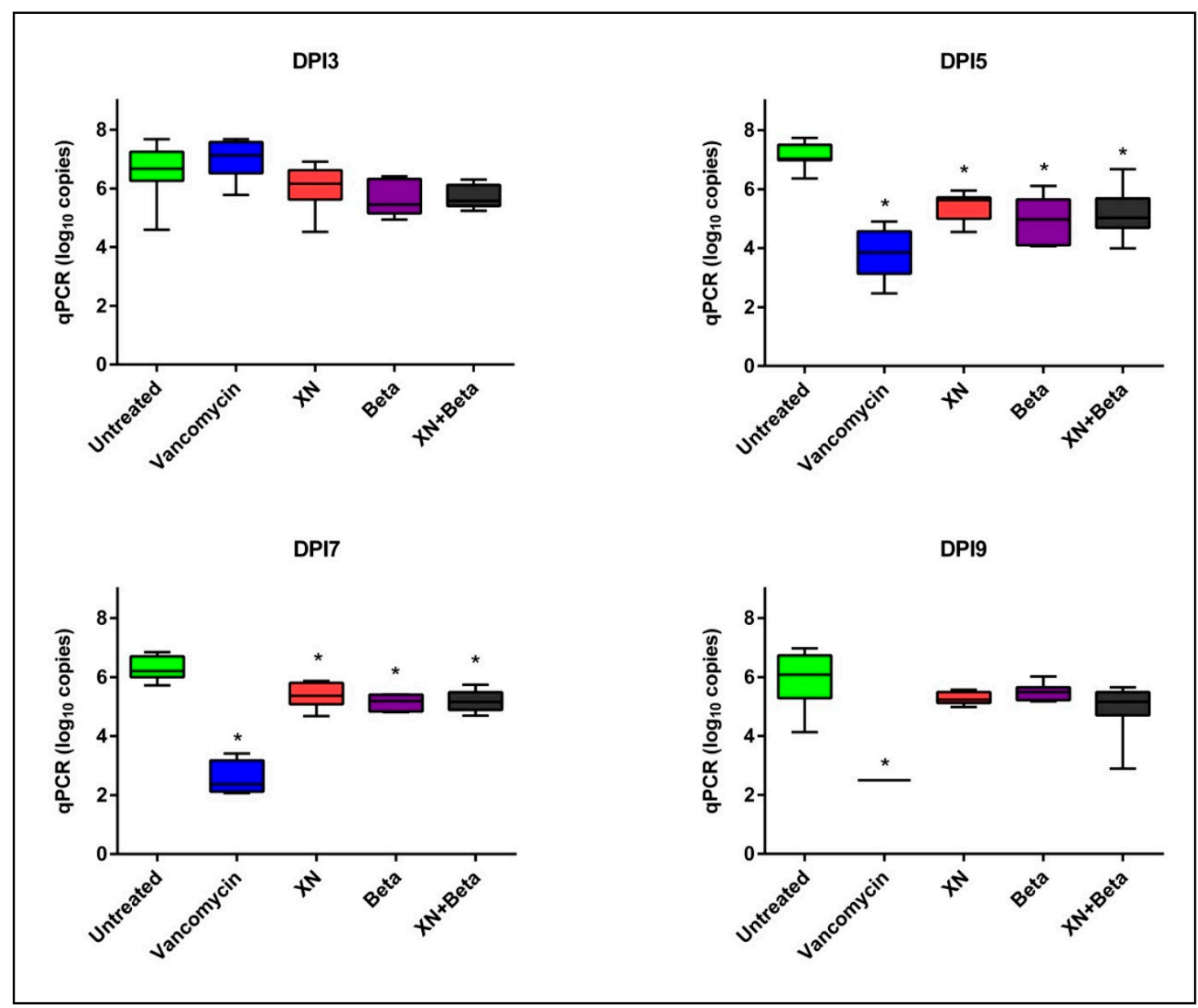

Figure 2. Bacterial load ( $\log _{10}$ copies per reaction) of $C$. difficile per $g$ of stool from rats. * Significant differences compared to untreated controls $(p<0.05)$. DPI-day post-infection, XN—xanthohumol, Beta-beta-acids.

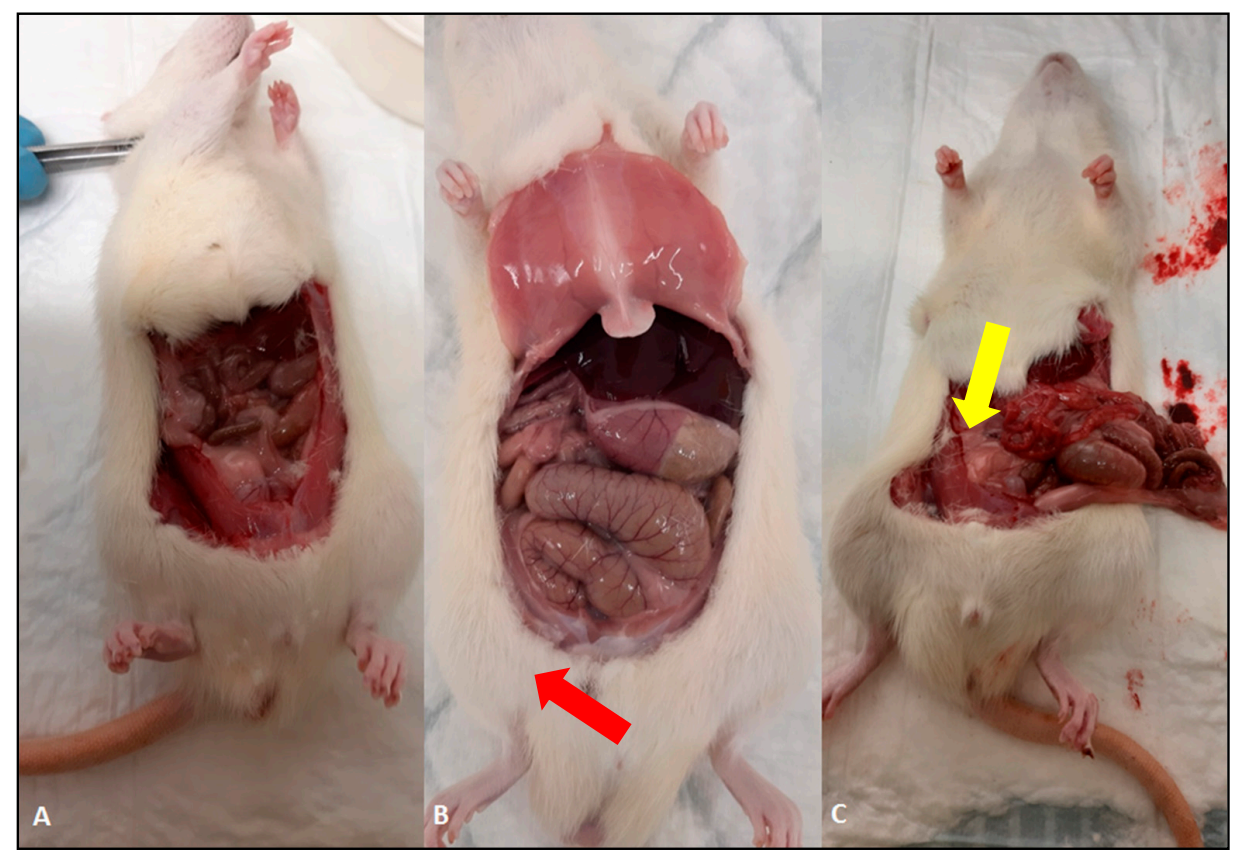

Figure 3. Macroscopical evaluation of $C$. difficile infection in the large and small intestines. (A) Normal macroscopical finding in the Xanthohumol treated rat; (B) edema in the large intestine (red arrow) and (C) hyperemia in the small intestine in infected untreated rats (yellow arrow). 
The histopathological samples were collected at the end of the experiment (day 10). Microscopical examination showed C. difficile infection-induced edema and leukocyte infiltration in the large intestine of untreated animals. These findings were significantly reduced by all treatments (examples shown in Figure 4).
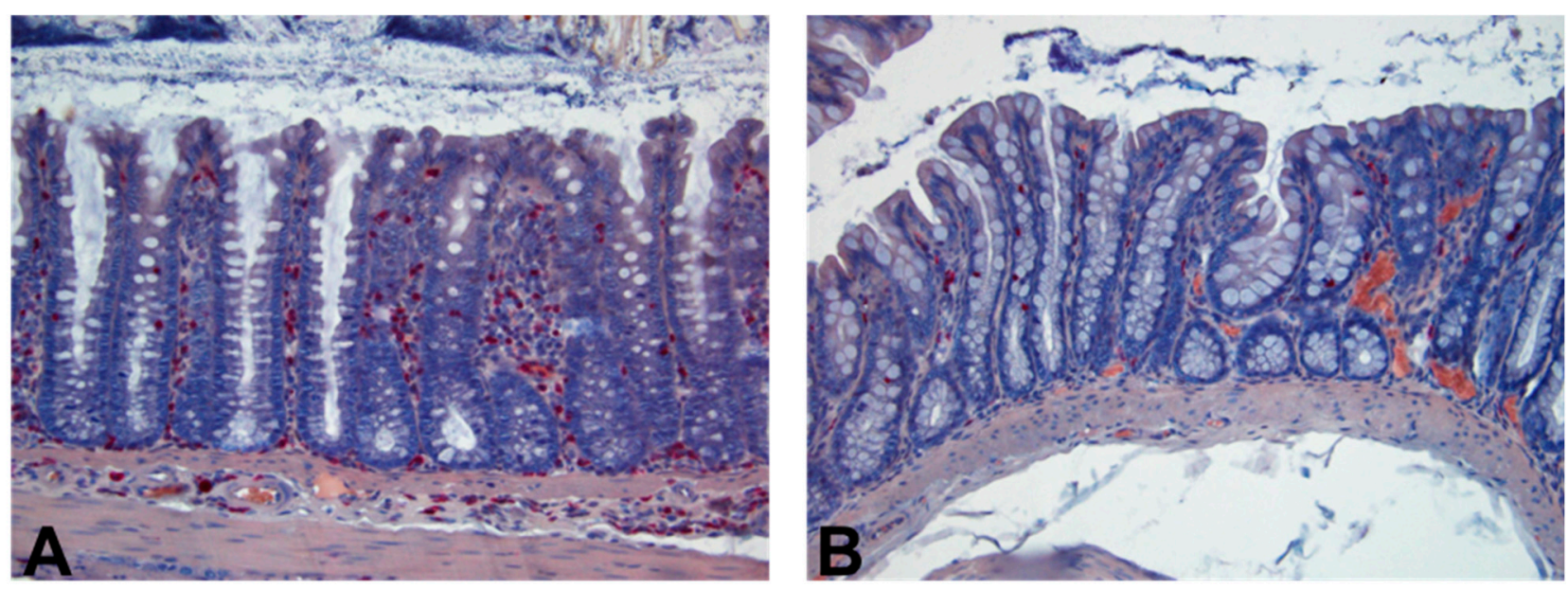

Figure 4. Histopathological changes in the colon from rats infected with C. difficile 10 days post-infection (A) with no treatment and (B) treated with xanthohumol. Tissue samples are stained with a naphthol AS-D chloroacetate kit and counterstained with hematoxylin (200-fold original magnification). C. difficile infection leads to high neutrophil infiltration (red color) and edema (A), which is substantially reduced by the xanthohumol treatment (B).

Further analysis showed (Figure 5) that treatments with xanthohumol or beta-bitter acids reduced the edema in the large intestine. Additionally, the individual compounds significantly reduced the histopathological score of inflammation. Quantitation of neutrophils in the mucosal and submucosal tissues showed that all treatment modalities led to significant decreases in the numbers of neutrophils per microscopic field.

The extent of histopathological changes in the small intestine of infected rats was generally low, even in untreated controls (data not shown).

Taken together, xanthohumol and beta-bitter acids show a clear antimicrobial effect against $C$. difficile infection in vivo, leading to both notable decreases in bacterial load (significant especially at days 5 and 7 post-infection) and normalization of inflammatory markers in the mucosal and submucosal tissues of the large intestine. The best antimicrobial effects in this model in vivo are obtained with the administration of either xanthohumol alone or a mixture of xanthohumol and beta-bitter acids from hops. In addition, the developed and presented animal model in rats provides a useful tool in studies of the pathogenesis and therapy of colitis induced by $C$. difficile infection. 


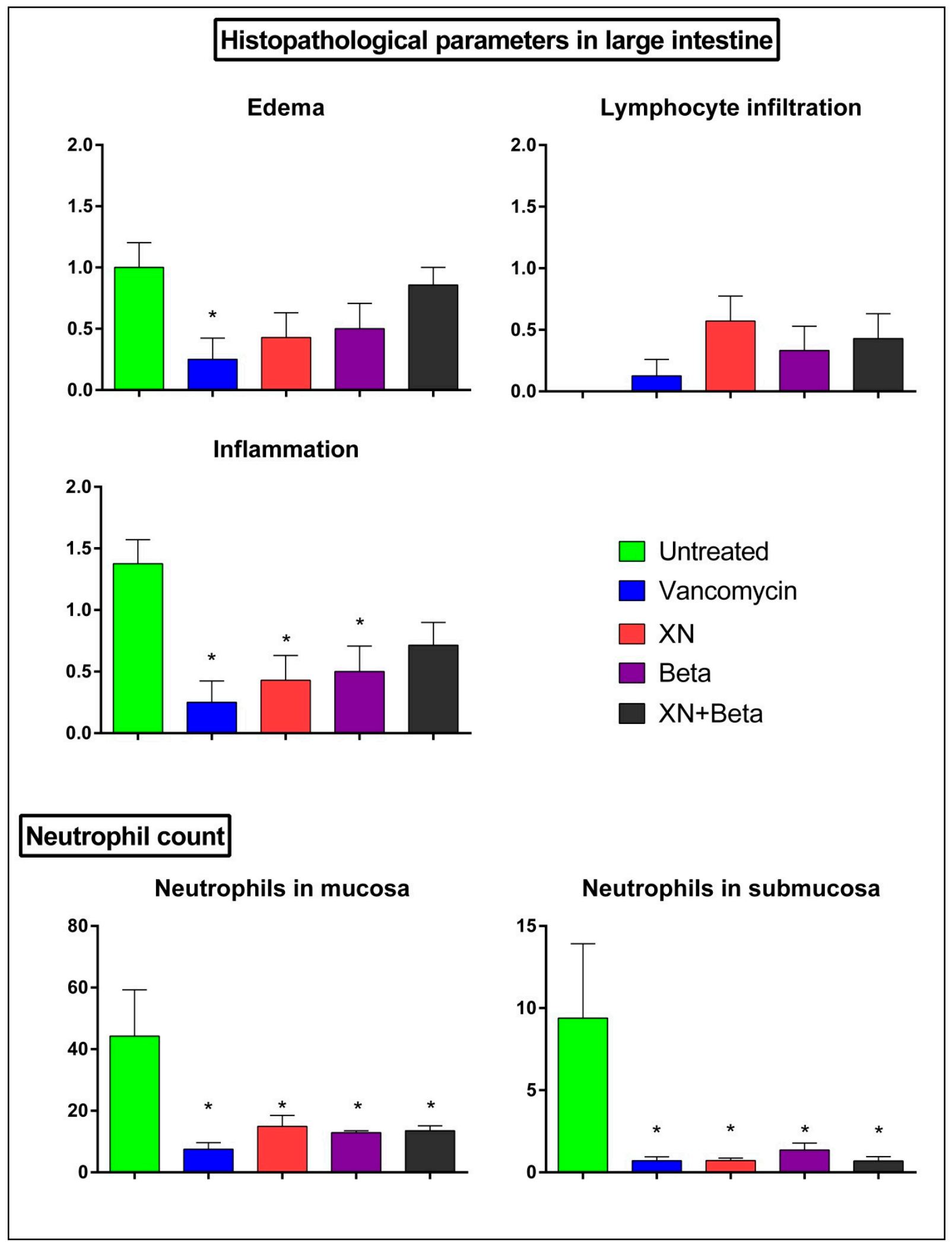

Figure 5. Histopathological analysis of the effect of treatments in large intestines of rats in the individual cohorts. Data are presented as mean \pm standard deviation. * indicates significant differences compared to untreated controls $(p<0.05)$. 


\section{Discussion}

C. difficile is one of the most common nosocomial pathogens with a worldwide distribution. It has been associated with pseudomembranous colitis, often leading to lifethreatening diarrhea with increased morbidity and mortality rates. The currently used therapeutic management of $C$. difficile infection is achieved by the termination of "unnecessary" antibiotics that may lead to the development of the condition and administration of antimicrobials effective against $C$. difficile. The currently used ones are represented by vancomycin and metronidazole. However, the infection has a relatively high recurrence rate. The recurrent disease and fulminant courses require an intra-intestinal or parenteral administration of antibiotics. Some drugs, such as metronidazole, are characterized by a high resorption rate and present with serious side effects. Thus, there is an ongoing search for alternative therapies for this disease. One of those is, for example, the fecal microbial transplantation $[9,21,22]$.

Another possible approach explored is the use of compounds with antimicrobial effects available in commonly used plants. Numerous studies have shown that the hops cones represent an abundant source of components with apparent antimicrobial effects against certain bacteria, viruses, fungi, and protozoa. Some of the specific properties for using these hops derivatives as therapeutics is their low cytotoxicity, specifically for the use in the GIT, and their very low adsorption. These features lead to their safety and the absence of side effects. The antibacterial properties of some purified compounds from hops, namely xanthohumol and beta-bitter acids, were determined in vitro for many pathogens, including C. difficile, in the past [13].

In the present study, the efficiency of the treatment with two compounds isolated from hops and their mixture was tested in an animal model of the C. difficile-induced gastrointestinal infection. We first successfully established the rat model for the $C$. difficile bowel infection. In this model, the bacteria from the hypervirulent human strain were atraumatically introduced into the GIT of animals pre-conditioned with a regimen of antibiotics. In contrast to the hamster model historically used for $C$. difficile infection, the course of the infection in rats is not fulminant and lethal, which allows for an extended antimicrobial efficacy testing. Thus, the rat model is more similar to the disease course of C. difficile bowel infection in humans, which will allow not only for in vivo testing of novel antimicrobials but potentially for studies of disease pathogenesis as well.

The results of this study show that all the hops derivatives tested possess antimicrobial properties against the $C$. difficile infection in vivo. However, the pure xanthohumol exhibited higher antimicrobial potential in our model than the other hops compounds tested. It significantly decreased the bacterial load of $C$. difficile in fecal samples after two days of application. These results further corroborate our previously published data of the high in vitro activity of xanthohumol against $C$. difficile determined by the broth dilution method. Similar antimicrobial effects were observed for the combination of xanthohumol and beta-bitter acids. Treatments by these substances also had positive effects on body weight and other general signs of the disease in experimental animals compared to the untreated control.

Finally, this work illustrates the antimicrobial potential of the tested compounds against $C$. difficile in in vivo testing. These results show that namely xanthohumol has the potential of being developed into an antimicrobial treatment regimen or to be used in combination with standardly used drugs. The advantage of xanthohumol for such use is its minimal resorption in the intestine, thus allowing for the administration of large doses with no or minimal side effects.

Mechanisms underlying antimicrobial activity of hops-derived compounds have not been extensively studied. Several reports suggest that these compounds affect bacterial cell membrane integrity, interfere with fatty acid metabolism, and lead to an accumulation of protons intracellularly and subsequent cell starvation [23-25]. A combination of these mechanisms may underlie effects of these compounds against $C$. difficile observed in the presented study. However, the elucidation of the exact mechanism will need further 
investigation. Taken together, the results show the purified substances from hops are promising candidates for further development and use in difficult-to-treat infections in humans, such as colitis caused by C. difficile.

\section{Materials and Methods}

\subsection{Hops Compounds}

A pure isolate of beta-acids was prepared at the Hop Research Institute in Zatec and further purified at the Research Institute of Brewing and Malting according to the procedure described by Krofta et al. [26]. The first step involved partitioning the $\mathrm{CO}_{2}$ hops extract solution in an alkaline medium of sodium carbonate and sodium hydroxide to separate the alpha-acids and beta-acids fractions. In the next step, the crude beta-fraction has been used for the isolation of pure beta-acids $(99.7 \% w / w)$ through crystallization from the solvent mixture. The isolate of xanthohumol $(84.3 \% w / w)$ was prepared following the procedure described by Biendl [27]. The process consists of the selective sorption of prenylflavonoids from ethanolic hops extract on polyvinylpyrrolidone. The isolate contains, in addition to xanthohumol, the whole spectrum of different hops prenylflavonoids. A stock solution with a concentration of xanthohumol or beta-acids of $100 \mathrm{mg} / 1 \mathrm{~mL}$ was prepared by dissolving the isolates in dimethyl sulfoxide.

\subsection{Bacterial Strain and Culture Conditions}

The bacterial strain of $C$. difficile used in this study was from the collection of isolates of the Department of Medical Microbiology of Thomayer Hospital in Prague (Czech Republic). The hypervirulent strain 176 was isolated and ribotyped at the Institute of Microbiology, University Hospital and Second Medical Faculty, Charles University in Prague. The ribotype analysis was performed using PCR ribotyping and detection of the presence of toxin production governing genes (tcdA (A), tcdB (B), cdtA, and $\operatorname{cdtB}$ (binary)) was performed by a multiplex PCR. The strain was cultured on selective $C$. difficile blood agar (LabMediaServis, Jaromer, Czech Republic) supplemented with norfloxacin $(12 \mu \mathrm{g} / \mathrm{mL})$ and moxalactam $(32 \mu \mathrm{g} / \mathrm{mL})$. Bacterial stocks for cryopreservation were prepared on porous beads (ITEST, Hradec Kralove, Czech Republic). For each experiment, fresh bacterial culture was prepared as follows. The porous bead with $C$. difficile was inoculated onto the agar plate. The culture was performed under anaerobic conditions using an anaerobic gas chamber and an AnaeroGen sachet (Oxoid, Basingstoke, UK) at $37^{\circ} \mathrm{C}$ for $48 \mathrm{~h}$.

\subsection{Animals and Housing}

Male Wistar rats (weight 330-460 g) were purchased from VELAZ (Prague, Czech Republic). The animals were housed under veterinary control and standard conditions (light cycle $12 \mathrm{~h} / 12 \mathrm{~h}$, standard laboratory diet, and water ad libitum). All the experiments were performed with permission and under the supervision of the Ethics Committee of the Faculty of Military Health Sciences (Hradec Kralove, Czech Republic).

\subsection{Experimental Model}

The experimental animals were subjected to the following protocol to establish a suitable animal model for testing the compound's in vivo antibacterial activity. On day 5, water containing antibiotic mixture, consisting of amikacin $(9.66 \mathrm{mg} / \mathrm{kg}$, Braun Medical, Prague, Czech Republic), colistin (4.2 mg/kg, Teva Pharmaceuticals, Prague, Czech Republic), gentamicin (3.5 mg/kg, LONZA, Basel, Switzerland), metronidazole $(21.5 \mathrm{mg} / \mathrm{kg}$, Braun Medical, Prague, Czech Republic), and vancomycin ( $4.5 \mathrm{mg} / \mathrm{kg}$, Mylan SAS, Saint Priest, France), was given to each animal by intragastric gavage in a total volume of $1 \mathrm{~mL}$. This was followed with identical doses of amikacin, gentamicin, and colistin at day 2. A single dose of clindamycin (10 mg/kg; Fresenius Cabi, Germany) was given intraperitoneally at day 1 . On day 0 , the stool samples were sampled before the experimental bacterial infection to screen for any endogenous colonization with $C$. difficile. Then each rat was administered 
with a single dose of $C$. difficile suspension $\left(3 \times 10^{8}\right.$ cells in $\left.1 \mathrm{~mL}\right)$ by intragastric gavage. Rats were then monitored every day for general signs of infection (diarrhea, weight loss, and infection symptoms), and stool samples were collected for $C$. difficile identification until day 10 post-infection by culture and quantification at day 3, 5, 7, 9 post-infection by qPCR (Figure 6). For the evaluation of antibacterial effects of hops compounds, the animals were divided into 5 experimental groups of 7 animals each. There were two control groups: animals in the negative control group I received no antibacterial treatment, while those in the positive control group II received vancomycin $(150 \mathrm{mg} / \mathrm{L}$, Mylan SAS, St. Priest, France) as the "standard" antibiotic used in the treatment of pseudomembranous colitis. Animals in groups III, IV, and V were treated with xanthohumol, beta-bitter acids, or a mixture of both substances at the concentration $5 \mathrm{mg} / \mathrm{kg}$, respectively. All antibacterial agents were administered every day by intragastric gavage from day 3 post-infection. On day 10 post-infection, the animals were euthanized, and samples from the small and large intestine were collected for further histological examination.

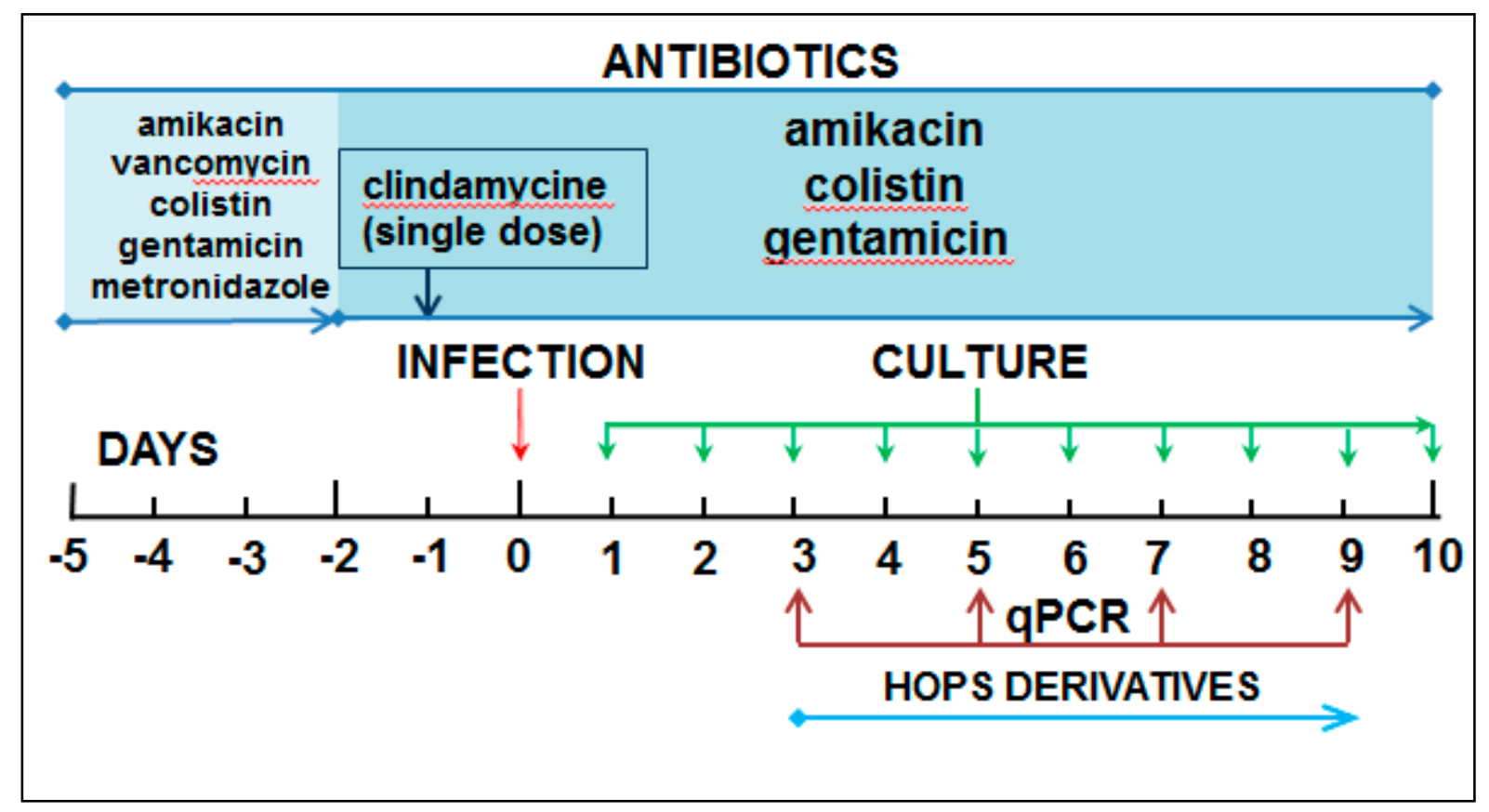

Figure 6. Time course of the experiment.

\subsection{DNA Isolation and Real-Time PCR}

The DNA from stool samples of rats was isolated by HigherPurity Stool DNA Isolation kit (Canvax Biotech S.L., Córdoba, Spain) according to the manufacturer's instructions. DNA samples were then stored at $-20^{\circ} \mathrm{C}$ until qPCR analysis.

The qPCR assay was performed using C. difficile Genesig Advanced Kit (PrimerDesign, Camberley, UK). The amplification reactions were carried out in a final volume of $20 \mu \mathrm{L}$, which consisted of $5 \mu \mathrm{L}$ of the template and $15 \mu \mathrm{L}$ of the master mix, containing Oasig 2X qPCR Master Mix, $300 \mathrm{nM}$ of each primer and $150 \mathrm{nM}$ fluorescence-labeled probe and distilled water. The assay was performed with the CFX Touch Real-Time PCR Detection System (Biorad, Hercules, CA, USA). The amplification conditions consisted of an initial enzyme activation at $95^{\circ} \mathrm{C}$ for $2 \mathrm{~min}$, followed by 50 cycles of denaturation at $95^{\circ} \mathrm{C}$ for $10 \mathrm{~s}$, primer annealing at $54^{\circ} \mathrm{C}$ for $30 \mathrm{~s}$, and data collection at $60^{\circ} \mathrm{C}$ for $1 \mathrm{~min}$. Fluorogenic data was collected through the FAM and VIC channels.

\subsection{Histopathology Examination}

Collected samples were fixed in 10\% neutral buffered formalin (Bamed, Ceske Budejovice, Czech Republic). Subsequently, they were histologically processed and stained 
with hematoxylin and eosin (both from Merck, Kenilworth, NJ, USA), according to Pejchal et al. [28]. The histopathological analysis was performed using a BX-51 microscope (Olympus, Tokyo, Japan) and a semiquantitative scale developer by Shelby et al. [20].

Neutrophil granulocytes were detected using Naphthol AS-D Chloroacetate (specific esterase) Kit (Sigma-Aldrich, St. Louis, MO, USA) according to the manufacturer's instructions. Naphthol AS-D Chloroacetate positive cells were measured in 6 randomly selected microscopic fields in the mucosal and submucosal compartments at 400 fold original magnification on a BX-51 microscope.

\subsection{Data Analysis}

Data obtained by the qPCR assay and weight monitoring were analyzed using Excel (Microsoft ${ }^{\circledR}$ 2010) software or imported into GraphPad Prism 6 (version 6.05, GraphPad Software Inc., San Diego, CA USA) for further analysis. The normality was tested using the Shapiro-Wilk test. Normally distributed data were analyzed using one-way ANOVA with post hoc Student's $t$-test. Non-normally distributed data were analyzed by Kruskal-Wallis test with post hoc Mann-Whitney test. The differences were considered significant when $p \leq 0.05$.

Author Contributions: Conceptualization, P.B., R.S. and P.C.; methodology, R.S., J.P. and V.R.; software, L.M.; validation, S.J., R.S. and J.P.; investigation, R.B., R.S. and V.R.; resources, A.M. and M.H.; data curation, R.S., V.R. and L.M.; writing—original draft preparation, R.S.; writing—review and editing, J.P. and P.B.; supervision, P.B.; funding acquisition, P.B. All authors have read and agreed to the published version of the manuscript.

Funding: This research was funded by the Czech Health Research Council of Czech Republic, grant NV-17-31765A and the Ministry of Defence of the Czech Republic-long-term organization development plan.

Institutional Review Board Statement: The study was conducted according to the guidelines of the Declaration of Helsinki and approved by the Ethics Committee of the Faculty of Military Health Sciences, Hradec Kralove, Czech Republic (protocol code MO 103191/2018-6848, date of approval 12 April 2018).

Informed Consent Statement: Not applicable.

Data Availability Statement: Data available on request due to ethical restrictions.

Conflicts of Interest: The authors declare no conflict of interest. The funders had no role in the design of the study, in the collection, analyses, or interpretation of data, in the writing of the manuscript, or in the decision to publish the results.

\section{References}

1. Oka, K.; Osaki, T.; Hanawa, T.; Kurata, S.; Sugiyama, E.; Takahashi, M.; Tanaka, M.; Taguchi, H.; Kamiya, S. Establishment of an Endogenous Clostridium difficile Rat Infection Model and Evaluation of the Effects of Clostridium butyricum MIYAIRI 588 Probiotic Strain. Front. Microbiol. 2018, 9, 1264. [CrossRef] [PubMed]

2. Shah, D.; Dang, M.D.; Hasbun, R.; Koo, H.L.; Jiang, Z.D.; DuPont, H.L.; Garey, K.W. Clostridium difficile infection: Update on emerging antibiotic treatment options and antibiotic resistance. Expert Rev. Anti-Infect. Ther. 2010, 8, 555-564. [CrossRef]

3. Zhu, D.; Sorg, J.A.; Sun, X. Clostridioides difficile Biology: Sporulation, Germination, and Corresponding Therapies for C. difficile Infection. Front. Cell. Infect. Microbiol. 2018, 8, 29. [CrossRef] [PubMed]

4. Janoir, C. Virulence factors of Clostridium difficile and their role during infection. Anaerobe 2016, 37, 13-24. [CrossRef] [PubMed]

5. Koenigsknecht, M.J.; Theriot, C.M.; Bergin, I.L.; Schumacher, C.A.; Schloss, P.D.; Young, V.B. Dynamics and establishment of Clostridium difficile infection in the murine gastrointestinal tract. Infect. Immun. 2015, 83, 934-941. [CrossRef] [PubMed]

6. Dharbhamulla, N.; Abdelhady, A.; Domadia, M.; Patel, S.; Gaughan, J.; Roy, S. Risk Factors Associated With Recurrent Clostridium difficile Infection. J. Clin. Med. Res. 2019, 11, 1-6. [CrossRef]

7. Dieterle, M.G.; Rao, K.; Young, V.B. Novel therapies and preventative strategies for primary and recurrent Clostridium difficile infections. Ann. N. Y. Acad. Sci. 2019, 1435, 110-138. [CrossRef] [PubMed]

8. Ooijevaar, R.E.; van Beurden, Y.H.; Terveer, E.M.; Goorhuis, A.; Bauer, M.P.; Keller, J.J.; Mulder, C.J.J.; Kuijper, E.J. Update of treatment algorithms for Clostridium difficile infection. Clin. Microbiol. Infect. 2018, 24, 452-462. [CrossRef]

9. Singh, T.; Bedi, P.; Bumrah, K.; Singh, J.; Rai, M.; Seelam, S. Updates in Treatment of Recurrent Clostridium difficile Infection. J. Clin. Med. Res. 2019, 11, 465-471. [CrossRef] 
10. Wilcox, M.H.; Gerding, D.N.; Poxton, I.R.; Kelly, C.; Nathan, R.; Birch, T.; Cornely, O.A.; Rahav, G.; Bouza, E.; Lee, C.; et al. Bezlotoxumab for Prevention of Recurrent Clostridium difficile Infection. N. Engl. J. Med. 2017, 376, 305-317. [CrossRef]

11. Bartmanska, A.; Walecka-Zacharska, E.; Tronina, T.; Poplonski, J.; Sordon, S.; Brzezowska, E.; Bania, J.; Huszcza, E. Antimicrobial Properties of Spent Hops Extracts, Flavonoids Isolated Therefrom, and Their Derivatives. Molecules 2018, 23, 2059. [CrossRef]

12. Bogdanova, K.; Roderova, M.; Kolar, M.; Langova, K.; Dusek, M.; Jost, P.; Kubelkova, K.; Bostik, P.; Olsovska, J. Antibiofilm activity of bioactive hop compounds humulone, lupulone and xanthohumol toward susceptible and resistant staphylococci. Res. Microbiol. 2018, 169, 127-134. [CrossRef] [PubMed]

13. Cermak, P.; Olsovska, J.; Mikyska, A.; Dusek, M.; Kadleckova, Z.; Vanicek, J.; Nyc, O.; Sigler, K.; Bostikova, V.; Bostik, P. Strong antimicrobial activity of xanthohumol and other derivatives from hops (Humulus lupulus L.) on gut anaerobic bacteria. APMIS 2017, 125, 1033-1038. [CrossRef] [PubMed]

14. Jeliazkova, E.; Zheljazkov, V.D.; Kacaniova, M.; Astatkie, T.; Tekwani, B.L. Sequential Elution of Essential Oil Constituents during Steam Distillation of Hops (Humulus lupulus L.) and Influence on Oil Yield and Antimicrobial Activity. J. Oleo Sci. 2018, 67, 871-883. [CrossRef] [PubMed]

15. Mody, D.; Athamneh, A.I.M.; Seleem, M.N. Curcumin: A natural derivative with antibacterial activity against Clostridium difficile. J. Glob. Antimicrob. Resist. 2020, 21, 154-161. [CrossRef] [PubMed]

16. Roehrer, S.; Behr, J.; Stork, V.; Ramires, M.; Medard, G.; Frank, O.; Kleigrewe, K.; Hofmann, T.; Minceva, M. Xanthohumol C, a minor bioactive hop compound: Production, purification strategies and antimicrobial test. J. Chromatogr. B Analyt. Technol. Biomed. Life Sci. 2018, 1095, 39-49. [CrossRef] [PubMed]

17. Best, E.L.; Freeman, J.; Wilcox, M.H. Models for the study of Clostridium difficile infection. Gut Microbes 2012, 3, 145-167. [CrossRef]

18. De Wolfe, T.J.; Kates, A.E.; Barko, L.; Darien, B.J.; Safdar, N. Modified Mouse Model of Clostridioides difficile Infection as a Platform for Probiotic Efficacy Studies. Antimicrob. Agents Chemother. 2019, 63, e00111-19. [CrossRef] [PubMed]

19. Deng, H.; Yang, S.; Zhang, Y.; Qian, K.; Zhang, Z.; Liu, Y.; Wang, Y.; Bai, Y.; Fan, H.; Zhao, X.; et al. Bacteroides fragilis Prevents Clostridium difficile Infection in a Mouse Model by Restoring Gut Barrier and Microbiome Regulation. Front. Microbiol. 2018, 9 , 2976. [CrossRef]

20. Shelby, R.D.; Tengberg, N.; Conces, M.; Olson, J.K.; Navarro, J.B.; Bailey, M.T.; Goodman, S.D.; Besner, G.E. Development of a Standardized Scoring System to Assess a Murine Model of Clostridium difficile Colitis. J. Investig. Surg. 2020, 33, 887-895. [CrossRef] [PubMed]

21. Gupta, S.; Allen-Vercoe, E.; Petrof, E.O. Fecal microbiota transplantation: In perspective. Ther. Adv. Gastroenterol. 2016, 9, 229-239. [CrossRef] [PubMed]

22. Hui, W.; Li, T.; Liu, W.; Zhou, C.; Gao, F. Fecal microbiota transplantation for treatment of recurrent C. difficile infection: An updated randomized controlled trial meta-analysis. PLoS ONE 2019, 14, e0210016. [CrossRef] [PubMed]

23. Bocquet, L.; Sahpaz, S.; Bonneau, N.; Beaufay, C.; Mahieux, S.; Samaillie, J.; Roumy, V.; Jacquin, J.; Bordage, S.; Hennebelle, T.; et al. Phenolic Compounds from Humulus lupulus as Natural Antimicrobial Products: New Weapons in the Fight against Methicillin Resistant Staphylococcus aureus, Leishmania mexicana and Trypanosoma brucei Strains. Molecules 2019, 24, 1024. [CrossRef]

24. Karabin, M.; Hudcova, T.; Jelinek, L.; Dostalek, P. Biologically Active Compounds from Hops and Prospects for Their Use. Compr. Rev. Food Sci. Food Saf. 2016, 15, 542-567. [CrossRef]

25. Cheon, D.; Kim, J.; Jeon, D.; Shin, H.C.; Kim, Y. Target Proteins of Phloretin for Its Anti-Inflammatory and Antibacterial Activities Against Propionibacterium acnes-Induced Skin Infection. Molecules 2019, 24, 1319. [CrossRef]

26. Krofta, K.; Liskova, H.; Vrabcova, S. Process for Preparing Pure Beta Acids of Hop. Patent Number CZ303017B6, 29 February 2012.

27. Biendl, M. Isolation of Prenylflavovnoids from Hops. International Society for Horticultural Science. Available online: http: / /www.actahort.org/books/1010/1010_15.htm (accessed on 15 January 2021).

28. Pejchal, J.; Novotny, J.; Marak, V.; Osterreicher, J.; Tichy, A.; Vavrova, J.; Sinkorova, Z.; Zarybnicka, L.; Novotna, E.; Chladek, J.; et al. Activation of p38 MAPK and expression of TGF-beta1 in rat colon enterocytes after whole body gamma-irradiation. Int. J. Radiat. Biol. 2012, 88, 348-358. [CrossRef] [PubMed] 